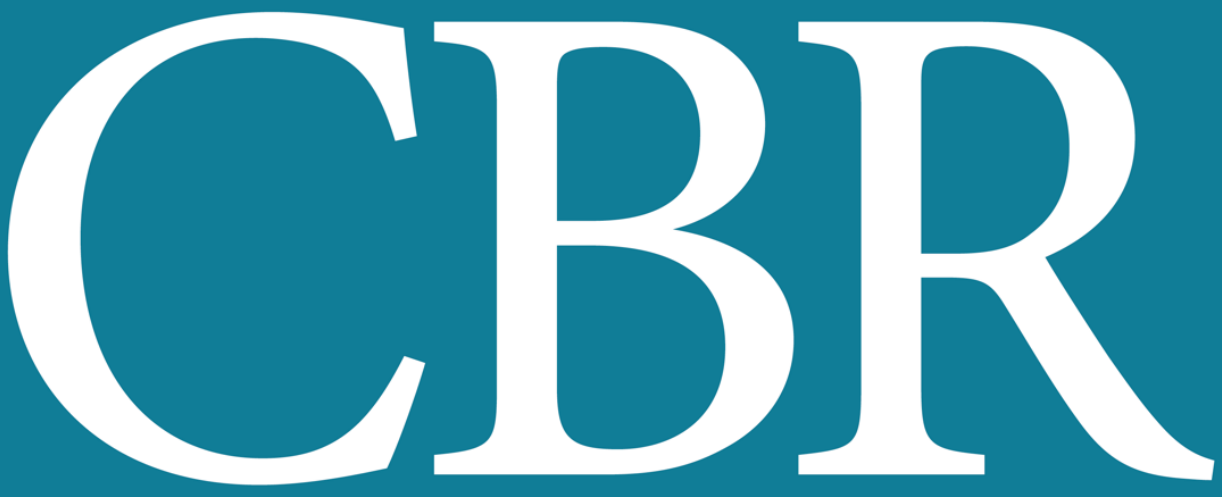

INTERNATIONAL JOURNAL OF CANCER AND BIOMEDICAL RESEARCH

https://jcbr.journals.ekb.eg

Editor-in-chief

Prof. Mohamed Labib Salem, PhD

Role of serum miR-21 and miR-92a in colorectal cancer diagnosis as novel molecular biomarkers

Ramy A. Hassan, Mohamed I. Omar, Mahmoud R. Shehata, Mohamad Raafat, Ali Hamdy, Ali Zedan and Murad A Jabir 


\section{Welcome letter from Editor-in-Chief}

Welcome to the Int J Cancer and Biomedical Research (IJCBR)!

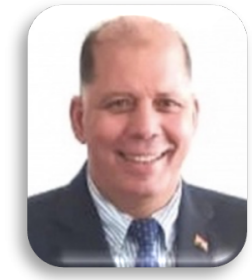

It is with great pleasure that I write this editorial to welcome you to the IJCBR. This journal provides a platform for publication of original and reviews research articles, short communications, letter to editor, thesis abstract, conference report, and case studies. These types of publication are directed at the interface of the fields of cancer and biomedical research.

The IJCBR relies on a distinguished expert of the Advisory and Editorial Board Members from the top international league covering in depth the related topics. They timely review all manuscripts and maintain highest standards of quality and scientific methodology and ethical concepts. Meanwhile, we take all possible means to keep the time of the publication process as short as possible.

I take this chance to welcome your contributions to the IJCBR and have every expectation that it will soon become one of the most respected journals in both the fields of cancer and biomedical research.

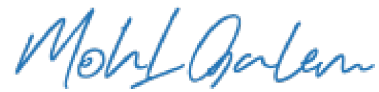

Mohamed L. Salem,

Editor in Chief 


\title{
Role of serum miR-21 and miR-92a in colorectal cancer diagnosis as novel molecular biomarkers
}

\author{
Ramy A. Hassan ${ }^{1}$, Mohamed I. Omar ${ }^{2}$, Mahmoud R. Shehata ${ }^{1}$, Mohamad Raafat ${ }^{1}$, Ali Hamdy ${ }^{3}$, Ali Zedan ${ }^{2}$ and \\ Murad A Jabir ${ }^{2}$ \\ ${ }^{1}$ General Surgery Department, Faculty of Medicine, Assiut University, Egypt \\ ${ }^{2}$ Surgical Oncology Department, South Egypt Cancer Institute, Assiut University, Egypt \\ ${ }^{3}$ Clinical Pathology Department, Faculty of Medicine, Assiut University, Egypt
}

\section{ABSTRACT}

Background: Our study aimed to evaluate the clinical utility of detecting plasma microRNAs (miR-21 \& miR-92a) for diagnosis of colorectal cancer patients and its relation to tumor staging. Patients and Methods: Quantitative real-time RT-PCR was applied to determine the relative expression level of miR-21 and miR-92a in serum. The sensitivity and specificity of these markers were evaluated by receiver operating characteristic (ROC) curve analysis. Final staging of colorectal cancer cases was assigned according to results of histopathologic examination of surgically resected specimens. Results: This study included 52 cases of colorectal cancer (CRC), 20 cases of precancerous colorectal lesions, and 20 healthy controls. Both Plasma miR-21 and Plasma miR-92a were significantly higher in CRC group compared to both the control group and precancerous group. Also, they were significantly higher in advanced CRC stages than early CRC stages. The sensitivity and specificity of miR-21 for discriminating CRC from controls were found to be $90.38 \%$ and $100.0 \%$, respectively. However, for miR-92a, sensitivity and specificity were found to be $94.23 \%$ and $100.0 \%$, respectively. For discriminating CRC cases from precancerous lesions, the sensitivity and specificity of miR-21 were found to be $75.08 \%$ and $95.0 \%$, respectively. However, for miR-92a, sensitivity and specificity were found to be $80.77 \%$ and $100.0 \%$, respectively. Conclusions: both plasma miR-21 and miR-92a have significant value for early detection of CRC as non-invasive screening molecular biomarkers with high sensitivity and specificity. They also help for differentiation between patients with benign and malignant colorectal lesions and those with early and advanced CRC.

Keywords: Biomarkers; Colorectal Cancer; Micrornas; miR-21; miR-92a

\section{ID ARTICLE INFO}

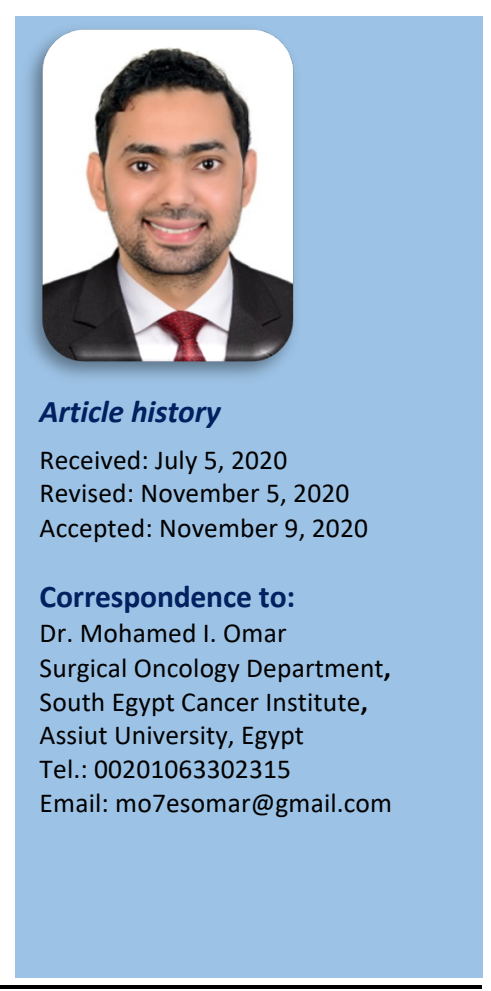

Editor-in-Chief: Prof. M.L. Salem, Ph.D. - Article DOI: 10.21608/JCBR.2020.34838.1049

\section{INTRODUCTION}

The incidence of colorectal cancer (CRC) is globally increasing especially in the western world and now ranks at $3^{\text {rd }}$ commonest cancer (Rawla et al., 2019). Late presentation and delayed diagnosis in a more advanced stage are associated with a very poor prognosis. Early diagnosis and initiation of therapy are associated with the best chances of cure. This can be reflected in a reduction of mortality from CRC (Keane and Johnson, 2012).

The main screening tools advocated by many surgeons for early detection of colorectal lesions are colonoscopy, CT colonography, and barium enema. However, their widespread application is limited. This could be attributed to their high-cost and invasive nature (Brenner et al., 2014). Therefore, there is a great demand for a less invasive test for the early diagnosis of CRC (Zhang et al., 2018). Currently, there are few serum biomarkers used for screening or early detection of CRC with variable sensitivity and specificity levels (Herreros-Villanueva et al., 2019).

MicroRNAs are small non-coding RNAs that have an important role in the regulation of cell differentiation, mitosis, apoptosis, and carcinogenesis (Croce and Calin, 2005; Aslam et al., 2009). They act at the posttranscriptional 
level by binding to target mRNA, preventing its translation, or by transcriptional gene silencing (He and Hannon 2004; Hede 2005). Regarding carcinogenesis, microRNAs act as oncogenes or tumor-suppressor genes. They have a key role in cancer progression, including CRC (Calin et al., 2002; He et al., 2005; Schetter et al., 2008; Ng et al., 2009).

Certain microRNAs have been evaluated as biomarkers for CRC diagnosis. A few of them were selectively expressed in CRC, such as upregulation of miR-21 and miR-92a and downregulation of miR-422a (Clancy et al., 2015; Zekri et al., 2016). Only a few studies have evaluated the role of serum microRNAs as biomarkers for CRC diagnosis at an early stage with contradictory results (Schetter et al., 2008; Chen et al., 2013; Liu et al., 2013; Toiyama et al., 2013).

This study aimed to evaluate the clinical utility of detecting plasma microRNAs (miR-21 \& miR92a) for diagnosis of colorectal cancer patients \& their relation to tumor staging as well as their use in diagnosing a benign colorectal condition and differentiating it from colorectal cancer.

\section{PATIENT AND METHODS}

This is a prospective cohort study that included patients undergoing colonoscopic examination for lower Gl symptoms at endoscopy units at South Egypt Cancer Institute and Assiut University Hospital in the period (January 2018 - December 2018). Practical work was carried out at the Clinical Pathology Department, Assiut University Hospital. The study was approved by the Institutional review board (IRB) of the Faculty of Medicine - Assiut University with IRB no. 2018-0127. All participants had informed written consent. All age groups were included. Patients with colorectal cancer that had been received chemotherapy, radiotherapy, or surgical treatment were excluded. Patients with a history of malignant tumors in other organs were also excluded from the study.

\section{Grouping of patients}

Patients were categorized according to colonoscopic and histopathologic findings into 3 groups:

Group A: patients with pathologic-proven colorectal cancer.
Group B: patients with precancerous benign colorectal lesions.

Group C: patients with normal colonoscopic findings (Control Group).

Diagnostic workup: All participants were subjected to the following:

- Clinical history and clinical examination including the digital rectal examination (DRE).

- Multi-Slice CT abdomen and pelvis.

- Full Colonoscopy.

- Pathological examination of colorectal mass biopsy.

\section{Sample collection}

Two $\mathrm{ml}$ of blood were sampled into EDTA coated tube centrifuged at $1000 \mathrm{rpm}$ for $5 \mathrm{~min}$, and then plasma was transferred into an RNase-free tube for RNA extraction. Plasma was stored at $-80^{\circ} \mathrm{C}$ until assay.

Determination of plasma miR-21 and miR-92a by (qRT-PCR): According to the manufacturer's instructions, total RNA purification (including small RNAs) was done using the miRNeasy Mini Kit (Cat. No. 217004): QIAGEN that was stored dry at room temperature $\left(15-25^{\circ} \mathrm{C}\right)$. Real-time PCR for detection of mature miR-21 and miR92a was done by using 7500 fast real-time PCR "Applied Biosystems"-USA. RNA extraction was carried out using miRNeasy Mini Kit (Cat. No. 217004; Qiagen - Germany), according to the manufacturer's instructions. Extracted RNA was subjected to RNA quantitation and purity assessment using NanoDrop ${ }^{\circledR}$ (ND)-1000 spectrophotometer (NanoDrop Technologies, Inc., Wilmington, DE, USA). miRNAs reverse transcription into complementary DNA was performed using miScript ${ }^{\circledR}$ II RT Kit (Cat. No. 218161; Qiagen - Germany), according to the manufacturer's instructions which were stored at $-20^{\circ} \mathrm{C}$.

For detection of mature miRNA, CDNA prepared in a reverse transcription reaction using miScript HiSpec Buffer serves as the template for real-time PCR analysis using miRNA-specific miScript Primer Assay (forward primer) and the miScript SYBR Green PCR Kit, which contains the miScript Universal Primer (reverse primer) and QuantiTect SYBR Green PCR Master Mix (Cat. No. 218073; Qiagen - Germany), (composed of 
HotStarTaq ${ }^{\circledR}$ DNA polymerase, QuantiTect SYBR Green PCR Buffer, dNTP Mix, including dUTP, SYBR Green I, ROX ${ }^{\mathrm{TM}}$ passive reference dye and $5 \mathrm{~mm} \mathrm{MgCl2}$ ). Cycling conditions for real-time PCR included PCR initial activation step for 15 minutes at $95^{\circ} \mathrm{C}$, denaturation for 15 seconds at $94{ }^{\circ} \mathrm{C}$, annealing for 30 seconds at $55^{\circ} \mathrm{C}$, and extension for 30 seconds at $70^{\circ} \mathrm{C}$. This included a total of 50 cycles.

Interpretation of results: Cycle threshold (Ct) values were automatically calculated using the Rotor Gene ${ }^{\circledR}$ Q software 2.1 (Qiagen Germany). Relative gene expression levels were normalized to a housekeeping gene (SNORD 68) and the fold change (FC) of expression or relative quantitation for the targeted miRNAs was calculated using the $2^{-\Delta \Delta C T}$ method.

Surgical intervention: Patients with histopathologic proven colorectal cancer or those with lesions with high-grade dysplasia underwent standard surgical resection according to the site of the mass either by conventional colectomy or complete mesocolic excision colectomy using open or laparoscopic approaches. The final staging was assigned according to results of histopathologic examination of resection specimens, reported according to AJCC TNM staging $-7^{\text {th }}$ edition. Patients with familial polyposis coli (FAP) were treated by total procto-colectomy with ileal pouch-anal anastomosis. Patients with stage IV colorectal cancer were omitted from surgical resection except for those who need palliation e.g. obstructed cases.

Statistical analysis: Data were analyzed using SPSS- version 21. Chi-square was used to compare the difference in the distribution of frequencies among different groups. For variables with more than two categories; the ANOVA test was calculated to test the mean differences of the data that follow a normal distribution and independent sample. KruskalWallis was used to compare the median difference between groups that do not follow the normal distribution. A P-value of less than 0.05 was considered significant. The P-value of post-hoc test was calculated using Bonferroni corrections. ROC curve was depicted the diagnostic performance of biomarkers for diagnosis of CRC, analyzed as the area under the curve (AUC). Validity statistics (sensitivity, specificity, positive, and negative predictive value) were calculated.

\section{RESULTS}

The study included fifty-two newly diagnosed colorectal cancer patients, twenty patients with precancerous benign colorectal diseases, and twenty age and sex-matched controls.

Patients groups: CRC group: 52 patients with colorectal cancer:

- 15 patients with CRC TNM stage I.

- 17 patients with CRC TNM stage II.

- 12 patients with CRC TNM stage III.

- 8 patients with CRC TNM stage IV.

Precancerous group: 20 patients with precancerous colorectal diseases:

- 7 patients with advanced adenoma.

- 6 patients with ulcerative colitis.

- 5 patients with Crohn's disease.

- 2 patients with familial adenomatous polyposis.

Control group: 20 individuals with normal colonoscopic findings were selected as a control group for comparison.

There was no significant difference among the 3 studied groups regarding age, gender, or occupation. However, smoking was significantly higher in CRC cases than the precancerous group and in healthy controls (Table 1 ).

microRNAs levels: Both Plasma miR-21 and Plasma miR-92a (fold change) were significantly higher in CRC group compared to both the control group and precancerous group, with a pvalue $<0.001$ for each. Also, they were significantly higher in the precancerous group compared to the control group, with a $\mathrm{p}$-value < 0.001 (Table 2).

Comparison of CRC biomarkers (Early CRC vs. Precancerous): Both Plasma miR-21 and Plasma miR-92a (fold change) were significantly higher in the early CRC group (TNM stages I \& II) compared to the precancerous group, with a $\mathrm{p}$ value $<0.001$ (Table 3 )

Comparison of CRC biomarkers (Early CRC vs. Adenoma): Both Plasma miR-21 and Plasma miR-92a (fold change) were significantly higher in the early CRC group (TNM stages I \& II) 
compared to adenoma group, with $\mathrm{p}$-value $=$ 0.015 and 0.002 , respectively (Table 4).

Comparison of CRC biomarkers (Early CRC vs. Advanced (RC): Both Plasma miR-21 and Plasma miR-92a (fold change) were significantly higher in advanced CRC (stages III \& IV) compared to early CRC (TNM stages I \& II), with a $p$-value $<0.05$ (Table 5).

Diagnostic performance of CRC biomarkers (CRC vs. Control): To determine the optimum diagnostic cut-off value and evaluate the sensitivity of circulating plasma miR-21 and miR92a for diagnosis of CRC vs. healthy controls, Receiver Operating Characteristic (ROC) analysis was performed. Table 6 shows the diagnostic performance data in form of sensitivity, specificity, NPV, and PPV for miR-21 (at a cutoff value of $>2.31 \mathrm{FC}$ ) and miR-92a (at a cutoff value of $>2.76 \mathrm{FC}$ ) and combined use of both markers. These results confirm that combined plasma miR-21 and miR-92a are more sensitive and have higher diagnostic accuracy and NPV than plasma miR-92a which is more sensitive and has higher diagnostic accuracy and NPV than plasma miR-21 in discriminating CRC cases from healthy controls. Both plasma miR-21 and miR-92a have the highest specificity and PPV (Table 6).
Diagnostic performance of CRC biomarkers (CRC vs. Precancerous): To determine the optimum diagnostic cut-off value and evaluate the sensitivity of circulating plasma miR-21 and miR-92a for diagnosis of CRC vs. precancerous benign colorectal diseases, ROC analysis was performed. Table 7 showed the diagnostic performance data in form of sensitivity, specificity, NPV, and PPV for miR-21 (At a cut-off value $>6.44 \mathrm{FC}$ ) and miR-92a (At a cut-off value $>5.76 \mathrm{FC}$ ) and combined use of both markers. These results confirm that combined plasma miR-21 and miR-92a are more sensitive, specific, and have higher diagnostic accuracy and NPV than plasma miR-92a which is more sensitive, specific, and has higher diagnostic accuracy and NPV than plasma miR-21 in discriminating CRC cases from precancerous benign colorectal cases. Plasma miR-92a has the highest PPV (Table 7).

Correlation between CRC Biomarkers in patients' groups:

- In precancerous cases: Both miR-21 and miR-92a revealed significant positive correlation ( $r$-value $=0.805$, $p$-value $<0.001$ ) (Table 8).

- In CRC cases: Both miR-21 and miR-92a revealed significant positive correlation ( $r$ value $=0.690 \& p$-value $<0.001)$. (Table 8$)$.

Table 1. Socio-demographic data among the studied groups

\begin{tabular}{|c|c|c|c|}
\hline & $\begin{array}{c}\text { CR } \\
(n=52)\end{array}$ & $\begin{array}{l}\text { Precancerous } \\
(n=20)\end{array}$ & $\begin{array}{c}\text { Control } \\
(n=20)\end{array}$ \\
\hline \multicolumn{4}{|l|}{ Age/years } \\
\hline - Mean \pm SD & $52.67 \pm 10.7$ & $53.15 \pm 11.1$ & $53.75 \pm 13.5$ \\
\hline - Median (Range) & $51(33-79)$ & $52(38-70)$ & $53(35-78)$ \\
\hline$p$-value & $\mathrm{P}_{1}=0.720^{\mathrm{NS}}$ & $\mathrm{P}_{2}=0.874^{\mathrm{NS}}$ & $P_{3}=0.868^{N S}$ \\
\hline \multicolumn{4}{|l|}{ Sex } \\
\hline - Male & $33(63.5 \%)$ & $12(60 \%)$ & $9(45 \%)$ \\
\hline - Female & $19(36.5 \%)$ & $8(40 \%)$ & $11(55 \%)$ \\
\hline$p$-value & $P_{1}=0.359^{\mathrm{NS}}$ & $P_{2}=0.467^{N S}$ & $P_{3}=0.384^{\mathrm{NS}}$ \\
\hline \multicolumn{4}{|l|}{ Occupation } \\
\hline - Non-working & 25 (48.1\%) & $10(50 \%)$ & $8(40 \%)$ \\
\hline - Working & 27 (51.9\%) & $10(50 \%)$ & $12(60 \%)$ \\
\hline $\mathrm{p}$-value & $P_{1}=0.784^{N S}$ & $P_{2}=0.885^{N S}$ & $P_{3}=0.842^{\mathrm{NS}}$ \\
\hline \multicolumn{4}{|l|}{ Smoking } \\
\hline - No & 40 (76.9\%) & 12 (60\%) & 20 (100\%) \\
\hline - Yes & $12(23.1 \%)$ & $8(40 \%)$ & $0(0 \%)$ \\
\hline$p$-value & $P_{1}=0.009 *$ & $P_{2}=0.023 *$ & $P_{3}=0.017^{*}$ \\
\hline
\end{tabular}


Table 2. CRC biomarkers among the studied groups

\begin{tabular}{|c|c|c|c|}
\hline & $\begin{array}{c}\text { CRC } \\
(n=52)\end{array}$ & Precancerous $(n=20)$ & $\begin{array}{l}\text { Control } \\
(n=20)\end{array}$ \\
\hline \multicolumn{4}{|l|}{ miR-21 (fold change) } \\
\hline - Mean \pm SD & $12.91 \pm 14.52$ & $3.36 \pm 2.00$ & $1.00 \pm 0.66$ \\
\hline - Median (Range) & $8.4(0.9-84.7)$ & $3.2(0.5-7.8)$ & $0.8(0.1-2.3)$ \\
\hline$p$-value & $\mathrm{P}_{1}<0.001^{*}$ & $P_{2}<0.001^{*}$ & P3 $<0.001 *$ \\
\hline \multicolumn{4}{|l|}{ miR-92a (fold change) } \\
\hline - Mean \pm SD & $12.71 \pm 11.05$ & $3.08 \pm 1.61$ & $1.00 \pm 0.67$ \\
\hline - Median (Range) & $9.5(1.2-63.1)$ & $3.2(0.6-5.8)$ & $0.8(0.3-2.8)$ \\
\hline $\mathrm{p}$-value & $\mathrm{P}_{1}<0.001^{*}$ & $\mathrm{P}_{2}<0.001^{*}$ & $P_{3}<0.001^{*}$ \\
\hline
\end{tabular}

Table 3. CRC biomarkers (Early CRC vs. Precancerous)

\begin{tabular}{lccc}
\hline & $\begin{array}{c}\text { Precancerous } \\
(\mathbf{n}=\mathbf{2 0})\end{array}$ & $\begin{array}{c}\text { Early CRC } \\
(\mathbf{n}=\mathbf{3 2})\end{array}$ & p-value \\
\hline $\begin{array}{l}\text { miR-21 (fold change) } \\
\text { - Mean } \pm \text { SD }\end{array}$ & $3.36 \pm 2.00$ & $9.81 \pm 7.97$ & $<0.001^{*}$ \\
$\begin{array}{l}\text { - Median (Range) } \\
\text { miR-92a (fold change) }\end{array}$ & $3.2(0.5-7.8)$ & $8.0(0.9-32.8)$ & \\
$\begin{array}{l}\text { - Mean } \pm \text { SD } \\
\text { - Median (Range) }\end{array}$ & $3.08 \pm 1.61$ & $9.09 \pm 5.70$ & $<0.001^{*}$ \\
\hline
\end{tabular}

Table 4. CRC biomarkers (Early CRC vs. Adenoma)

\begin{tabular}{lccc}
\hline & $\begin{array}{c}\text { Adenoma } \\
(\mathbf{n}=\mathbf{7})\end{array}$ & $\begin{array}{c}\text { Early CRC } \\
(\mathbf{n}=\mathbf{3 2})\end{array}$ & p-value \\
\hline miR-21 (fold change) & & & \\
- Mean \pm SD & $3.79 \pm 2.18$ & $9.81 \pm 7.97$ & $0.015^{*}$ \\
- Median (Range) & $3.9(0.8-7.8)$ & $8.0(0.9-32.8)$ & \\
miR-92a (fold change) & & & \\
- Mean \pm SD & $3.45 \pm 1.66$ & $9.09 \pm 5.70$ & $0.002^{*}$ \\
- Median (Range) & $3.2(0.9-5.8)$ & $7.2(1.2-27.5)$ & \\
\hline & *Statistically Significant
\end{tabular}

Table 5. CRC biomarkers (Early CRC vs. Advanced CRC)

\begin{tabular}{cccc}
\hline & $\begin{array}{c}\text { Early CRC } \\
(\mathbf{n = 3 2 )}\end{array}$ & $\begin{array}{c}\text { Advanced CRC } \\
(\mathbf{n = 2 0})\end{array}$ & p-value \\
\hline \multicolumn{4}{c}{ miR-21 (fold change) } \\
- Mean \pm SD & $9.81 \pm 7.97$ & $17.88 \pm 20.50$ & $<0.05^{*}$ \\
- Median (Range) & $8.0(0.9-32.8)$ & $11.1(3.5-84.7)$ & \\
miR-92a (fold change) & & \\
- Mean \pm SD & $9.09 \pm 5.7$ & $18.5 \pm 14.74$ & $<0.05^{*}$ \\
- Median (Range) & $7.2(1.2-27.5)$ & $13.7(4.4-63.1)$ & \\
\hline & *Statistically Significant
\end{tabular}

Table 6. Diagnostic performance (CRC vs. Control)

\begin{tabular}{llll}
\hline & miR-21 & miR-92a & $\begin{array}{l}\text { Combined } \\
\text { miR-21\&92a }\end{array}$ \\
\hline Cut-off value & $>2.31 \mathrm{FC}$ & $>2.76 \mathrm{FC}$ & \\
AUC & 0.977 & 0.991 & 0.981 \\
Accuracy, \% & 93.06 & 95.83 & 97.22 \\
Sensitivity, \% & 90.38 & 94.23 & 96.15 \\
Specificity, \% & 100.0 & 100.0 & 100.0 \\
PPV, \% & 100.0 & 100.0 & 100.0 \\
NPV, \% & 80.0 & 87.0 & 90.9 \\
\hline
\end{tabular}

* Sensitivity (true positives/all diseased); specificity (true negatives/all non-diseased); PPV (true positives/all test positives); NPV (true negatives/all test negatives).
Table 7. Diagnostic performance (CRC vs. Precancerous)

\begin{tabular}{rccc}
\hline & miR-21 & miR-92a & $\begin{array}{c}\text { Combined } \\
\text { miR-21\&92a }\end{array}$ \\
\hline Cut-off value & $>6.44 \mathrm{FC}$ & $>5.76 \mathrm{FC}$ & \\
AUC & 0.867 & 0.927 & 0.917 \\
Accuracy, \% & 80.56 & 86.11 & 90.28 \\
Sensitivity, \% & 75.08 & 80.77 & 88.46 \\
Specificity, \% & 95.0 & 100.0 & 95.0 \\
PPV, \% & 97.5 & 100.0 & 97.9 \\
NPV, \% & 59.4 & 66.7 & 76.0 \\
\hline
\end{tabular}

*Sensitivity (true positives/all diseased); specificity (true negatives/all non-diseased); PPV (true positives/all test positives); NPV (true negatives/all test negatives). 
Table 8. Correlation between miR biomarkers

\begin{tabular}{|c|c|c|}
\hline \multirow{2}{*}{ Precancerous } & miR-21 & \\
\hline & $r$-value & $p$-value \\
\hline \multirow[t]{4}{*}{ miR-92a } & 0.805 & $<0.001^{*}$ \\
\hline & $\operatorname{miR}-21$ & \\
\hline & r-value & p-value \\
\hline & 0.690 & $<0.001^{*}$ \\
\hline
\end{tabular}

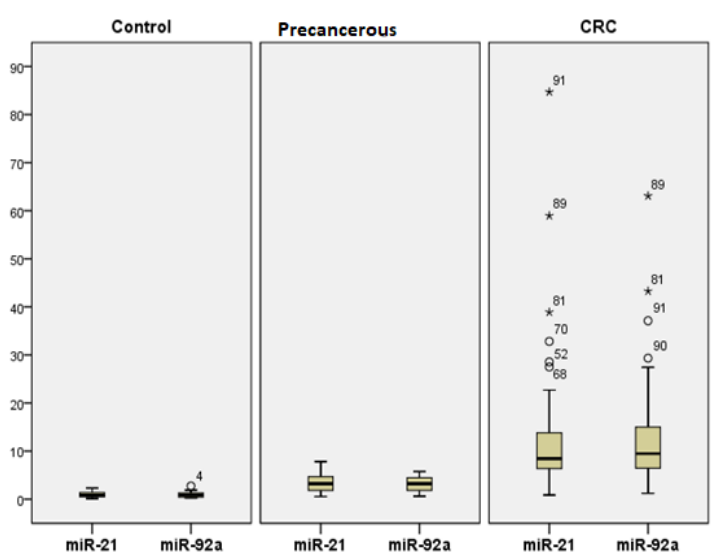

Figure 1. Box-Plot of miR-21 \& miR-92a among studied groups.

\section{DISCUSSION}

Levels of certain microRNAs have been reported to associate with diagnosis, prognosis, metastasis, and survival in multiple malignancies (Toiyama et al. 2013; Zhang et al. 2013; Neerincx et al. 2015). Circulating microRNAs are secreted from the cells in a highly stable form that can be detected in plasma. The remarkable stability, the feasibility of detection (rapid and accurate quantification), and the direct role of microRNAs in cancer pathogenesis make them ideal non-invasive biomarkers for early cancer diagnosis (Mitchell et al. 2008). We investigated the role of measuring plasma miR-21 and plasma miR-92a for the diagnosis of colorectal cancer disease and precancerous lesions. Our results exhibited significantly higher plasma miR-21 and miR-92a in CRC patients compared to both healthy controls and patients with precancerous benign colorectal diseases, with ( $P$-value $<0.001)$ for each. Also, plasma miR-21 and plasma miR-92a were significantly higher in patients with precancerous benign colorectal diseases compared to healthy controls, with P-value < 0.001 for each.
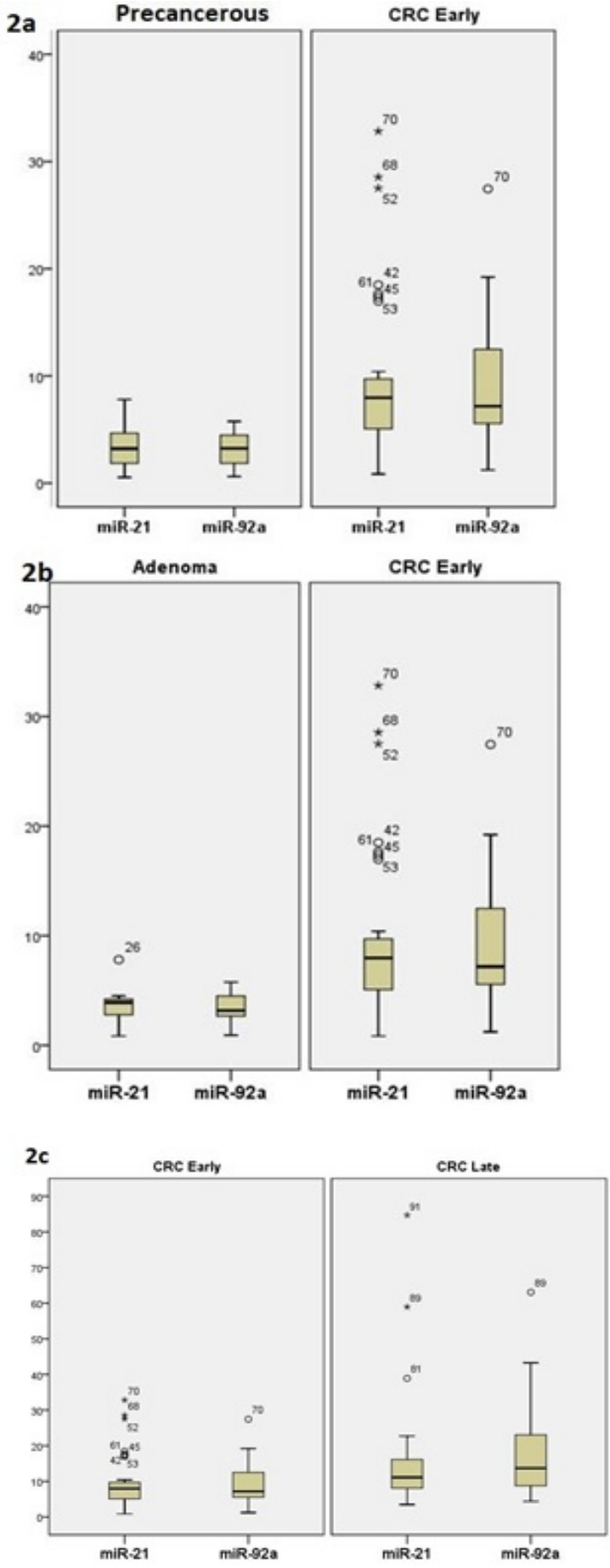

Figure 2. Box-Plot of miR-21 \& miR-92a for Early CRC vs. Precancerous (2a), Early CRC vs. Adenoma (2b), and Early CRC vs. advanced CRC (2c).

These data are consistent with those reported by many authors who found that miR-21 \& miR92a levels were significantly higher in CRC cases (Wang et al. 2014; Neerincx et al. 2015; Jepsen et al. 2016; Zhu et al. 2017). 

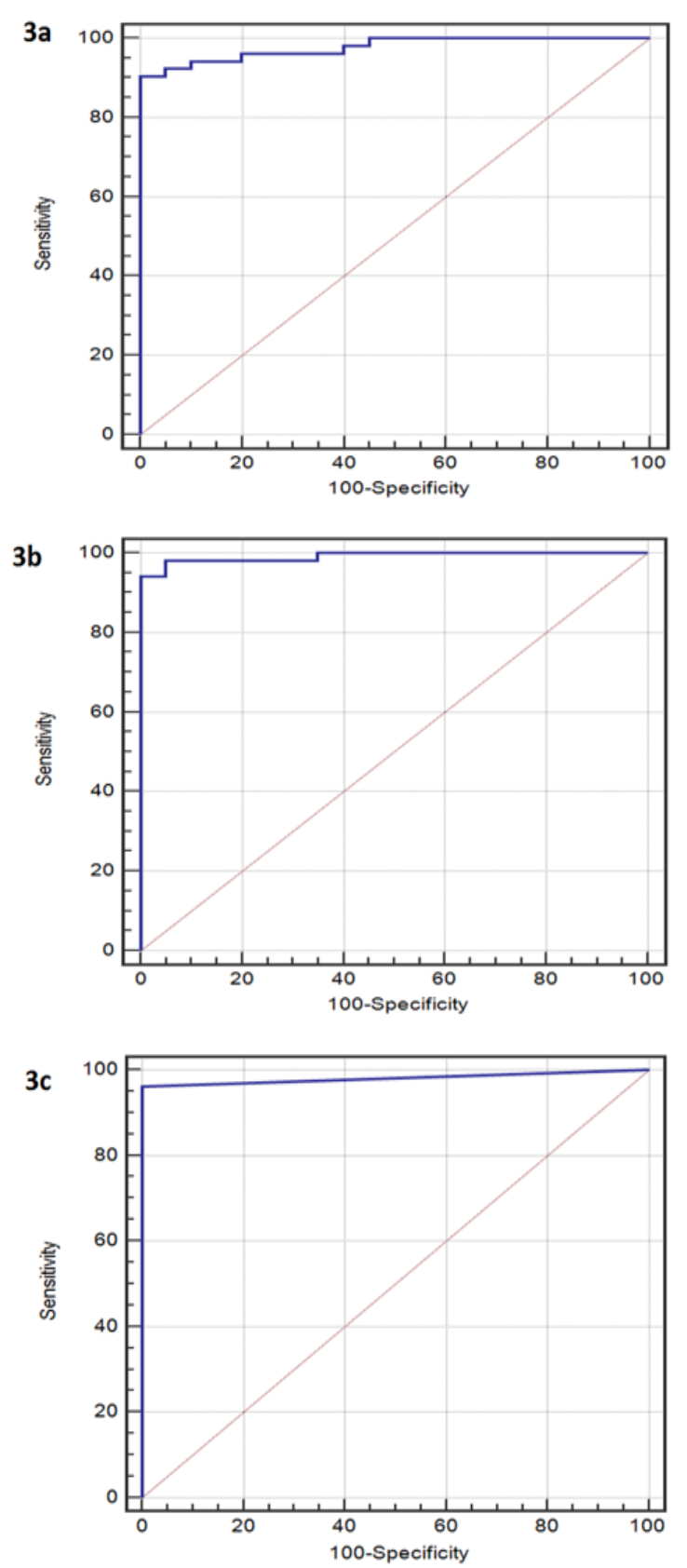

Figure 3. ROC curve for CRC vs. control of miR-21 (3a), miR-92a (3b), and combined microRNAs (3c).

A recent Chinese study reported that miR-21 is significantly up-regulated in adenomas and CRC tissues, compared with the normal mucosa (Wang et al. 2016). Similarly, another study reported elevated expression of serum miR-21. This finding was validated from an independent cohort, showing that miR-21 expression was markedly upregulated in preoperative serum from CRC patients, but its expression dropped in postoperative serum from patients who underwent curative surgical resection (Toiyama et al. 2013).
$4 a$

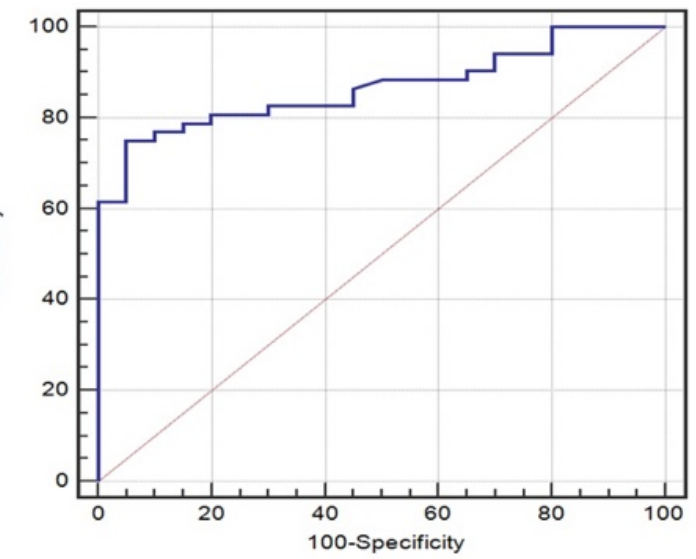

$4 b$

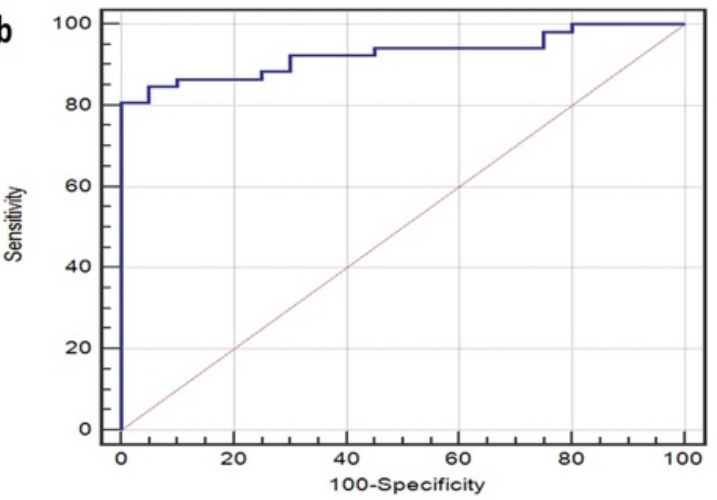

$4 c$

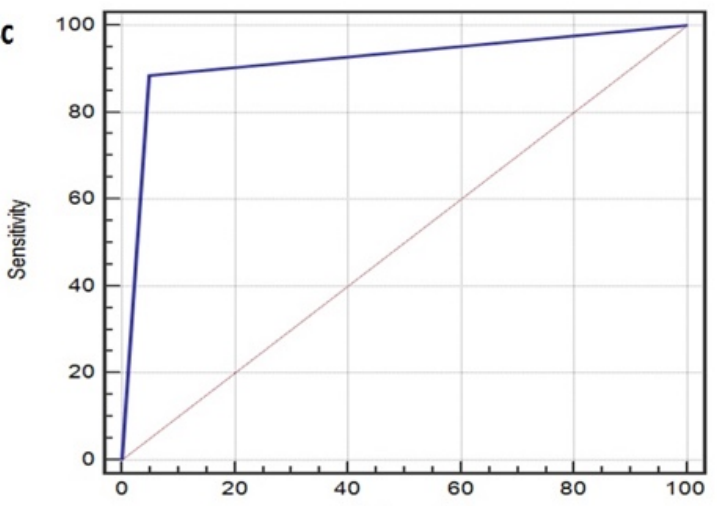

Figure 4. ROC curve for CRC vs. Precancerous of miR-21 (4a), miR-92a (4b) and combined microRNAs (4c).

Our data showed that there was a significantly higher plasma miR-21 and miR-92a in early CRC (TNM stages I \& II) patients compared to both healthy controls and patients with precancerous benign colorectal diseases, with P-value $<0.001$ for each. These results were similar to Ogata-Kawata et al. who showed higher serum levels of miR-21 in primary CRC patients, even early-stage disease (TNM stage I), than in controls, and were significantly decreased after surgical resection (OgataKawata et al. 2014). Recently, Zhang et al. reported that microRNA ratios; miR-21-5p/miR- 
367-3p and miR-92a-3p/miR135b can differentiate CRC cases from precancerous lesions and healthy controls (Zhang et al. 2018). Another study by Lee and Ferguson reported that miR-21 and miR-92a can identify the highrisk population for colorectal cancer. Therefore, these biomarkers could be used to identify those individuals who would benefit from preventive measures as lifestyle and dietary modifications (Lee and Ferguson 2016).

In our study, plasma miR-21 and miR-92a were significantly higher in advanced CRC (TNM stages III \& IV) compared to early CRC (TNM stages I \& II), with P-value $<0.05$ for each. This comes in agreement with Neerincx et al. who reported that the expression of miR-21 and miR92a was associated with more advanced TNM stages (Neerincx et al. 2015).

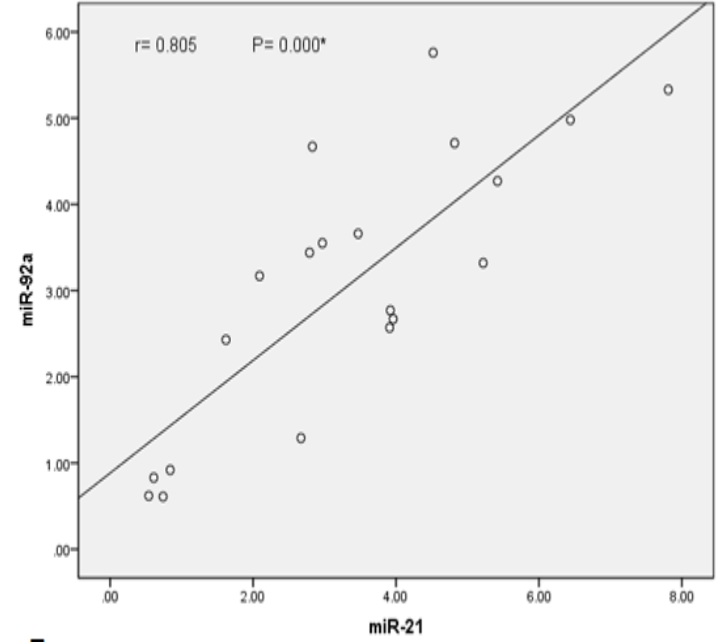

$5 a$

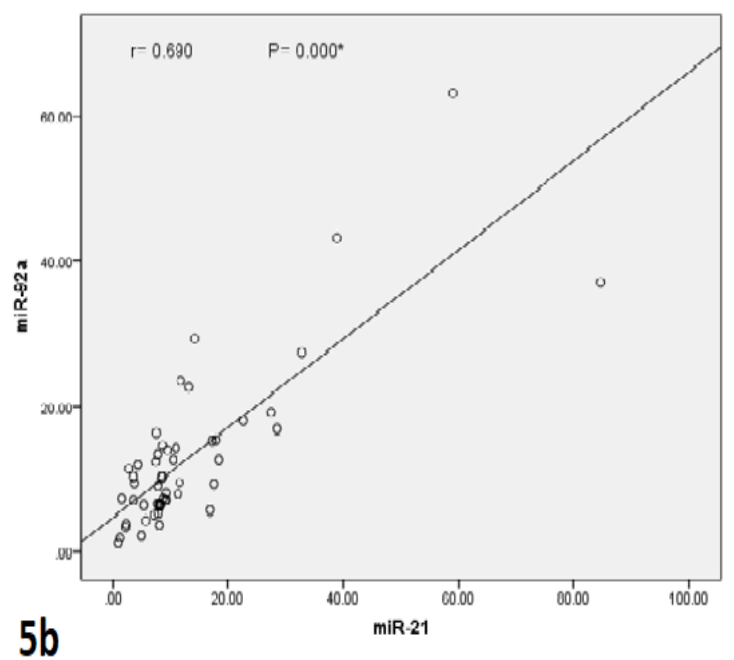

Figure 5. Correlation between miR-21 and miR-92a in the precancerous group (5a) and CRC group (5b).
Also, this is consistent with data from other investigators who reported that higher expression levels of miR-21 were associated with more advanced clinical stages of CRC (Schetter et al. 2008, Toiyama et al. 2013). Moreover, others reported miR-92a overexpression to correlate with colorectal cancer TNM stage, lymph node and distant metastases, and decreased survival of the patients (Liu et al. 2013, Yamada et al. 2013, Zhou et al. 2013). This could aid in the surgical decision as patients with stage III colonic cancer may benefit from the adoption of complete mesocolic excision. Also, patients with stage IV colorectal cancer with no signs of intestinal obstruction are managed primarily by chemotherapy. In our study, we constructed ROC analysis for discriminating CRC cases from healthy controls. At a cut-off value $>2.31$-fold change, plasma miR-21 was $90.38 \%$ sensitive and $100 \%$ specific, with AUC of 0.977 . Also, at a cut-off value $>2.76$-fold change, plasma miR92a was $94.23 \%$ sensitive and $100 \%$ specific, with the area under the curve (AUC) of 0.991. Moreover, combined plasma miR-21 and miR92a was $96.15 \%$ sensitive and $100 \%$ specific, with AUC of 0.981 .

Our results are promising and in agreement with Said et al. who reported that serum miR-21 at a cutoff value of $\geq 5.25$ was $94.3 \%$ sensitive and $93.3 \%$ specific for the diagnosis of CRC with an AUC of 0.995 and serum miR-92a at a cut-off value of $>6.75$, was $91.4 \%$ sensitive and $80 \%$ specific for the diagnosis of CRC with an AUC of 0.919 (Said et al. 2017). Similarly, Guo et al. reported that serum miR-21 effectively distinguished CRCs from healthy controls with 91.6\% sensitivity, $91.7 \%$ specificity, and AUC of 0.960 (Guo et al. 2018). Also, Wang et al. reported that serum miR-21 showed a sensitivity and specificity of $93 \%$ and 91\%, respectively (Wang et al. 2014). Furthermore, Ahmed et al. reported plasma miR-92a to have a sensitivity and specificity of $89 \%$ and $70 \%$ respectively at a cut-off value $>6.75$ in distinguishing CRC patients from healthy controls (Ahmed et al. 2012).

On the other hand, it was reported that the sensitivity of serum miR-21 for detection CRC was only $65 \%$ and the specificity was $85 \%$ (Liu et al. 2013). Also, Huang et al. reported similar 
results with plasma miR-92a; sensitivity and specificity of $84 \%$ and $71.4 \%$ respectively (Huang et al. 2010). In the present work, also we constructed ROC analysis for discriminating CRC cases from precancerous benign colorectal diseases. Moreover, combined plasma miR-21 and miR-92a were $88.46 \%$ sensitive and $95 \%$ specific, with AUC of 0.917 . These results were in agreement with Zhang et al. who reported that the microRNA ratio miR-21-5p/miR-367-3p can distinguish patients with CRC from those with adenoma, with an AUC of 0.797 (Zhang et al. 2018).

In conclusion, both plasma miR-21 and miR-92a had potential value for early detection of CRC as non-invasive screening molecular biomarkers with high sensitivity and specificity. They also help for differentiation between patients with benign and malignant colorectal lesions and those with early and advanced CRC.

\section{CONFLICT OF INTEREST}

Authors declare that they have no conflicts of interest.

\section{FUDING}

There is no financial support for this study.

\section{REFERENCES}

Ahmed FE, Amed NC, Vos PW, Bonnerup C, Atkins JN, Casey M, Nuovo GJ, Naziri W, Wiley JE, Allison RR 2012. Diagnostic microRNA markers to screen for sporadic human colon cancer in blood. Cancer Genomics Proteomics 9: 179192.

Aslam, M. I., Taylor, K., Pringle, J. H. and Jameson, J. S. (2009). "MicroRNAs are novel biomarkers of colorectal cancer." Br J Surg 96: 702-710.

Brenner, H., Stock, C. and Hoffmeister, M. (2014). "Effect of screening sigmoidoscopy and screening colonoscopy on colorectal cancer incidence and mortality: systematic review and meta-analysis of randomised controlled trials and observational studies." Bmj 348: g2467.

Calin, G. A., Dumitru, C. D., Shimizu, M., Bichi, R., Zupo, S., Noch, E., Aldler, H., Rattan, S., Keating, M., Rai, K., Rassenti, L., Kipps, T., Negrini, M., Bullrich, F. and Croce, C. M. (2002). "Frequent deletions and down-regulation of micro- RNA genes miR15 and miR16 at 13q14 in chronic lymphocytic leukemia." Proc Natl Acad Sci U S A 99: 15524-15529.

Chen, T. H., Chang, S. W., Huang, C. C., Wang, K. L., Yeh, K. T., Liu, C. N., Lee, H., Lin, C. C. and Cheng,
Y. W. (2013). "The prognostic significance of APC gene mutation and miR-21 expression in advanced-stage colorectal cancer." Colorectal Dis 15: 1367-1374.

Clancy, C., Joyce, M. R. and Kerin, M. J. (2015). "The use of circulating microRNAs as diagnostic biomarkers in colorectal cancer." Cancer Biomark 15: 103-113.

Croce, C. M. and Calin, G. A. (2005). "miRNAs, cancer, and stem cell division." Cell 122: 6-7.

Guo, S., Zhang, J., Wang, B., Zhang, B., Wang, X., Huang, L., Liu, H. and Jia, B. (2018). "A 5-serum miRNA panel for the early detection of colorectal cancer." Onco Targets Ther 11: 26032614.

He, L. and Hannon, G. J. (2004). "MicroRNAs: small RNAs with a big role in gene regulation." Nat Rev Genet 5: 522-531.

He, L., Thomson, J. M., Hemann, M. T., HernandoMonge, E., Mu, D., Goodson, S., Powers, S., Cordon-Cardo, C., Lowe, S. W., Hannon, G. J. and Hammond, S. M. (2005). "A microRNA polycistron as a potential human oncogene." Nature 435: 828-833.

Hede, K. (2005). "Studies define role of microRNA in cancer." J Natl Cancer Inst 97: 1114-1115.

Herreros-Villanueva, M., Duran-Sanchon, S., Martín, A. C., Pérez-Palacios, R., Vila-Navarro, E., Marcuello, M., Diaz-Centeno, M., Cubiella, J., Diez, M. S., Bujanda, L., Lanas, A., Jover, R., Hernández, V., Quintero, E., José Lozano, J., García-Cougil, M., Martínez-Arranz, I., Castells, A., Gironella, M. and Arroyo, R. (2019). "Plasma MicroRNA Signature Validation for Early Detection of Colorectal Cancer." Clin Transl Gastroenterol 10: e00003.

Huang, Z., Huang, D., S. Ni, Peng, Z., Sheng, W. and Du, X. (2010). "Plasma microRNAs are promising novel biomarkers for early detection of colorectal cancer." Int J Cancer 127: 118-126.

Jepsen, R. K., Novotny, G. W., Klarskov, L. L., Christensen, I. J., Høgdall, E. and Riis, L. B. (2016). "Investigating intra-tumor heterogeneity and expression gradients of miR21, miR-92a and miR-200c and their potential of predicting lymph node metastases in early colorectal cancer." Exp Mol Pathol 101: 187196.

Keane, M. G. and Johnson, G. J. (2012). "Early diagnosis improves survival in colorectal cancer." Practitioner 256: 15-18, 12.

Lee, K. and Ferguson, L. R. (2016). "MicroRNA biomarkers predicting risk, initiation and progression of colorectal cancer." World J Gastroenterol 22: 7389-7401.

Liu, G. H., Zhou, Z. G., Chen, R., Wang, M. J., Zhou, B., Li, Y. and Sun, X. F. (2013). "Serum miR-21 and 
miR-92a as biomarkers in the diagnosis and prognosis of colorectal cancer." Tumour Biol 34: 2175-2181.

Mitchell, P. S., Parkin, R. K., Kroh, E. M., Fritz, B. R., Wyman, S. K., Pogosova-Agadjanyan, E. L., Peterson, A., Noteboom, J., O'Briant, K. C., Allen, A., Lin, D. W., Urban, N., Drescher, C. W., Knudsen, B. S., Stirewalt, D. L., Gentleman, R., Vessella, R. L., Nelson, P. S., Martin, D. B. and Tewari, M. (2008). "Circulating microRNAs as stable blood-based markers for cancer detection." Proc Natl Acad Sci U S A 105: 1051310518.

Neerincx, M., Sie, D. L., van de Wiel, M. A., van Grieken, N. C., Burggraaf, J. D., Dekker, H., Eijk, P. P., Ylstra, B., Verhoef, C., Meijer, G. A., Buffart, T. E. and Verheul, H. M. (2015). "MiR expression profiles of paired primary colorectal cancer and metastases by next-generation sequencing." Oncogenesis 4: e170.

Ng, E. K., W. Chong, W., Jin, H., Lam, E. K., Shin, V. Y., J. Yu, Poon, T. C., Ng, S. S. and Sung, J. J. (2009). "Differential expression of microRNAs in plasma of patients with colorectal cancer: a potential marker for colorectal cancer screening." Gut 58: 1375-1381.

Ogata-Kawata, Izumiya, H., M., Kurioka, D., Honma, Y., Yamada, Y., Furuta, K., Gunji, T., Ohta, H., Okamoto, H., Sonoda, H., Watanabe, M., Nakagama, H., Yokota, J., Kohno, T. and Tsuchiya, N. (2014). "Circulating exosomal microRNAs as biomarkers of colon cancer." PLoS One 9: e92921.

Rawla, P., Sunkara, T. and Barsouk, A. (2019). "Epidemiology of colorectal cancer: incidence, mortality, survival, and risk factors." Przeglad gastroenterologiczny 14: 89-103.

Said, E., Zidan, A., Nawar, A., Alhusseini, N., Soliman, E., Shaker, R., Naguib, W., Rady, K. and Baiumy, H. (2017). "Circulating Micro RNA- 21 and - 92a as Biomarkers of Colorectal Cancer." AfroEgyptian Journal of Infectious and Endemic Diseases 7: 247-257.

Schetter, A. J., Leung, S. Y., Sohn, J. J., Zanetti, K. A., Bowman, E. D., Yanaihara, N., Yuen, S. T., Chan, T. L., Kwong, D. L., Au, G. K., Liu, C. G., Calin, G. A., Croce, C. M. and Harris, C. C. (2008). "MicroRNA expression profiles associated with prognosis and therapeutic outcome in colon adenocarcinoma." Jama 299: 425-436.

Toiyama, Y., Takahashi, M., Hur, K., Nagasaka, T., Tanaka, K., Inoue, Y., Kusunoki, M., Boland, C. R. and Goel, A. (2013). "Serum miR-21 as a diagnostic and prognostic biomarker in colorectal cancer." J Natl Cancer Inst 105: 849859.
Wang, J., Huang, S. K., Zhao, M., Yang, M., Zhong, J. L., Gu, Y. Y., Peng, H., Che, Y. Q. and Huang, C. Z. (2014). "Identification of a circulating microRNA signature for colorectal cancer detection." PLoS One 9: e87451.

Wang, X., Chen, L., Jin, H., Wang, S., Zhang, Y., Tang, $X$. and Tang, G. (2016). "Screening miRNAs for early diagnosis of colorectal cancer by small RNA deep sequencing and evaluation in a Chinese patient population." Onco Targets Ther 9: 1159-1166.

Yamada, N., Nakagawa, Y., Tsujimura, N., Kumazaki, M., Noguchi, S., Mori, T., Hirata, I., Maruo, K. and Akao, Y. (2013). "Role of Intracellular and Extracellular MicroRNA-92a in Colorectal Cancer." Transl Oncol 6: 482-492.

Zekri, A. R., Youssef, A. S., Lotfy, M. M., Gabr, R., Ahmed, O. S., Nassar, A., Hussein, N., Omran, D., Medhat, E., Eid, S., Hussein, M. M., Ismail, M. Y., Alenzi, F. Q. and Bahnassy, A. A. (2016). "Circulating Serum miRNAs as Diagnostic Markers for Colorectal Cancer." PLoS One 11: e0154130.

Zhang, J., Raju, G. S., Chang, D. W., Lin, S. H., Chen, Z. and Wu, X. (2018). "Global and targeted circulating microRNA profiling of colorectal adenoma and colorectal cancer." Cancer 124: 785-796.

Zhang, J. X., Song, W., Chen, Z. H., Wei, J. H., Liao, Y. J., Lei, J., Hu, M., Chen, G. Z., Liao, B., Lu, J., Zhao, H. W., Chen, W., He, Y. L., Wang, H. Y., Xie, D. and Luo, J. H. (2013). "Prognostic and predictive value of a microRNA signature in stage II colon cancer: a microRNA expression analysis." Lancet Oncol 14: 1295-1306.

Zhou, T., Zhang, G., Liu, Z., Xia, S. and Tian, H. (2013). "Overexpression of miR-92a correlates with tumor metastasis and poor prognosis in patients with colorectal cancer." Int J Colorectal Dis 28: 19-24.

Zhu, M., Huang, Z., Zhu, D., Zhou, X., Shan, X., Qi, L. W., Wu, L., Cheng, W., Zhu, J., Zhang, L., Zhang, Chen, H., Y., Zhu, W., Wang, T. and Liu, P. (2017). "A panel of microRNA signature in serum for colorectal cancer diagnosis." Oncotarget 8: 17081-17091. 


\section{Egyptian Association for Cancer Research (EACR)}

http://eacr.tanta.edu.eg/

EACR is an NGO society that was declared by the Ministry of Social Solidarity (Egypt) No. 1938 in 19/11/2014 based on the initiative of Prof. Mohamed Labib Salem, the current Chairman of EACR. EACR aims primarily to assist researchers, in particular young researchers in the field of cancer research through workshops, seminars and conferences. Its first international annual conference entitled "Anti-Cancer Drug Discovery" was successfully organized in April 2019 (http://acdd.tanta.edu.eg). Additionally, EACR aims to raise the awareness of the society about the importance of scientific research in the field of cancer research in prediction, early diagnosis and treatment of cancer. EACR is also keen to outreach the scientific community with periodicals and news on cancer research including peer-reviewed scientific journals for the publication of cutting-edge research. The official scientific journal of EACR is "International Journal of Cancer and biomedical Research (IJCBR: https://jcbr.journals.ekb.eg) was successfully issued in 2017 and has been sponsored by the Egyptian Knowledge Bank (EKB: www.ekb.eg).

\section{EACR Chairman,}

Prof. Mohamed Labib Salem, PhD

Professor of Immunology

Faculty of Science, Tanta Universiy, Egypt 
International Journal of Cancer and Biomedical Research (IJCBR), a publication of the Egyptian Association for Cancer Research (EACR), is a peer-reviewed online journal published quarterly. The journal allows free access (Open Access) to its contents and permits authors to self-archive a final accepted version of the articles on any OAl-compliant institutional / subject-based repository.

\section{Aim And Scope}

Aim: The main aim of IJCBR is to attract the best research in animal and human biology in health and diseases from across the spectrum of the biomedical sciences at the molecular, cellular, organ, and whole animal levels especially those that are related to cancer research, including causes, prediction, diagnosis, prognosis and therapy.

Scope: It is essential reading for all researchers interested in biochemistry, cancer, microbiology, nutrition, physiology, genetics, immunology, epidemiology, medical economics, human biology, bioinformatics, biotechnology, nanotechnology, and disease modeling.

\section{Publication Ethics}

Researchers should conduct their research from research proposal to publication in line with the best practices and codes of conduct of relevant professional bodies and/or national and international regulatory bodies. IJCBR accepts manuscripts prepared in accordance with the "Uniform Requirements for Submission of Manuscripts for Biomedical Journals adopted by the International Committee of Medical Journal Editors (ICMJE) and the Committee on Publication Ethics (COPE). Details of ICMJE and COPE are available at http://www.icmje.org/ and http://publicationethics.org/

\section{Peer Review Process}

After the IJCBR editor receives a manuscript, the first step is to confirm that the manuscript meets the journal's rules for content and format, including similarity check (plagiarism) which should be less than $25 \%$. If the manuscript meets the journal's rules, the editor then assign it to the double-blind peer review process. The IJCBR editor send the manuscript to at least two experts in the field for RIGOROUS scientific evaluation. The experts called peer reviewers - will then prepare a report that assesses the manuscript and return it to the editor through the IJCBR portal. Upon the first submission, this reviewing process takes about 4 to 6 weeks. After reading the peer reviewer's report, the editor will decide one of the following four options:

1. Reject the manuscript.

2. Accept the manuscript

3. Ask the authors to revise and resubmit the manuscript after responding to the peer reviewers' feedback.

4. Ask for peer-review from additional reviewers.

If the authors resubmit the manuscript, the IJCBR editor will ask the same peer-reviewers to look over the manuscript again to confirm that their concerns have been addressed. This is called re-review process. This second revision (if applicable) takes about another 4 to 6 weeks. At this point, the abstract of the article appears in press. The online publication (the PDF format) of the final version of the manuscript takes from 2 to 4 weeks. As such, the total publication cycle takes from 2 to 4 months. This cycle can be reduced to 4 to 6 weeks (fast track publication) for the manuscripts with outstanding findings.

The peer-review process used by IJCBR includes comments on errors in the study's methods or analysis that raise questions about the findings, or sections that need clearer explanations. The peer-review process also includes the importance and novelty of the manuscript and its interest to the journal's audience. The IJCBR uses double-blind review, which means that both the reviewers and authors identities are concealed from the reviewers, and vice versa, throughout the review process. To facilitate this, authors need to submit a Title Page containing the Authors details and Blinded Manuscript with no author details as 2 separate files. 


\section{Publisher}

The International Journal of Cancer and Biomedical Research (IJCBR) is an International and interdisciplinary journal of preclinical and clinical studies in the area of cancer and biomedical research. It is a peer-reviewed journal in English, published quarterly (in March, June, September, and December) by the Egyptian Association for Cancer Research (EACR) in both print and online formats (4 issues making a volume). Special issues or supplements may also be produced from time to time upon agreement with the Editorial Board.

\section{Scope}

The main aim of IJCBR is to attract the best research in animal and human biology in health and diseases from across the spectrum of the biomedical sciences at the molecular, cellular, organ, and whole animal levels especially those that are related to cancer research, including causes, prediction, diagnosis, prognosis and therapy.

\section{Publication Fees}

The journal does charge for submission, processing or publication of manuscripts (2000 LE for Egyptians or $\$ 300$ for non-Egyptians; EACR members receive 15\% discount on publication). Of them Peer-review fees (300 LE) should be paid on submission (non-refundable). For the fast track production of the accepted manuscript, another $500 \mathrm{LE}$ is paid.

General specifications for different types of article

- Submitted manuscripts should not have been published previously, except in a limited form (e.g. short communication to a symposium or as part of MSc or PhD theses) and should not be under consideration for publication by other journals.

- All co-authors should agree with the content of the manuscript. Authors must have obtained permission to use any copyrighted material in the manuscript before submission.

\section{IJCBR publishes different types of articles}

- Original Article (6000 words with $\mathbf{4}$ tables and $\mathbf{4}$ figures, maximum $\mathbf{8}$ display items): Articles with novel findings are the target of IJCBR. Articles presenting a detailed description of a new technique, comparison of existing methods, meta-analyses with comprehensive and in-depth discussion are considered. Papers in a numbered series are not accepted unless all are submitted at the same time.

- Short communications or case study (3000 words with 4 display items): Short communications present exceptionally exciting, novel or timely contents are considered. They will be peer-reviewed in the same way as research papers. The references are restricted to 15 .

- Reviews or systematic review (9000 words with $\mathbf{1 0}$ display items): They are invited by the Editorial Board or unsolicited. Review articles have to be contemporary and comprehensive and add information to the knowledge. Sharp critical analyses of novel data or concepts are encouraged. When relevant, a statistical analysis of data and a meta-analysis approach are recommended.

- Opinion papers, letter to the editor or comment to the editor (1500 words with $\mathbf{2}$ display items): They are submitted by invitation of the Editorial Board. They are short papers, which aim to inform scientists, industry, and the public and policymakers about cutting-edge issues in research or the impact of research. They reflect the opinion of their authors who bear full responsibility of the published paper. The references are restricted to 10 .

- Conference/Symposium papers: The journal will consider for publication the results of original work and critical reviews that are presented at conferences/symposia. Symposium organizers who wish to publish bundles of papers from a symposium/conference in IJCBR should first contact the Editor-inChief of the IJCBR (EACR@unv.tanta.edu.eg) for agreement. Supplementary material can be proposed and will be made available online. The responsibility for the preparation of a paper in a form suitable for publication lies with the author.

- Thesis: IJCBR can publish the summary and abstract of Master and PhD theses in a special issue. 
English: Good quality of written English is required. Spelling may be in British or American English but must be consistent throughout the paper. Care should be exercised in the use of biological terminology that is ill-defined or of local familiarity only. We recommend that authors have their manuscripts checked by an English language native speaker before submission.

Manuscript layout: Manuscripts should be prepared using a standard word processing program and presented in a clear readable format with easily identified sections and headings. The manuscript layout is based on the following directions.

- The main text contains Title, Abstract, Keywords, Introduction, Material and Methods, Results, Discussion, References, Tables, figures.

- The title needs to be concise and informative. Use bold, with an initial capital for the first word only and for words that ordinarily take capitals

- Short (running) title (max 80 characters including spacing).

- The article text should be typed with double-line spacing with wide margins $(2.5 \mathrm{~cm})$.

- The lines must be continuously numbered; the pages must also be numbered.

- Font Calibri 12 should be used for the text, and 12 for the tables, figure legends and references.

- The sections should typically be assembled in the following order:

- Title page contains title, authors' names, full affiliations, acknowledgements and the corresponding author's contacts and Short title.

Abstract (max 250 words, single paragraph): The abstract should be complete and understandable without citation, references, table or figure. Use structured abstract: Background, Aim, Materials \& Methods, Results and Conclusion. The context and the rationale of the study are presented succinctly to support the objectives. The experimental methods and main results are summarized but should not be overburdened by numerical values or probability values. The abstract ends with a short and clear conclusion.

Keywords: Up to five short and specific keywords should complement the title with respect to indicating the subject of the paper in alphabetic order.

Introduction: The introduction briefly outlines the context of the work, presents the current issues that the authors are addressing and the rationale to support the objectives, and clearly defines the objectives.

Material and methods: Material and methods should be described in sufficient details so that others can repeat the experiment. Reference to previously published work may be used to give methodological details, provided that said publications are readily accessible and in English. The code of ethics should be followed for all experiments use animals or human samples.

Statistical analysis of results: The statistical design and the models of statistical analysis must be described, as well as each of the statistical methods used. Sufficient statistical details must be given to allow replication of the statistical analysis. The experimental unit should be defined (e.g. individual or group of animals).

Results: Data are presented as tables and figures. Brief description of the results for each table and figure should be presented. Unpublished data can be mentioned when necessary.

Discussion: Should be separate from the Results section and should focus only on intra- and inter-data discussion (the data in the results section) as well as with the relative data in the literature. Don't repeat information already presented in the Introduction section. Start the first paragraph in the Discussion with a paragraph stating the rationale behind the study, the objectives and the main findings. End Discussion with a short conclusion.

Acknowledgements: In this section, the authors may acknowledge (briefly) their support staff.

Conflict of interest: All papers with a potential conflict of interest must include a description/explanation in a separate heading.

Funding details: The authors should state the source of findings of the study (with research funder and/or grant number). If no fund, the authors should state that the study is self-funded. 


\section{References}

Citation of references: In the text, references should be cited by the author(s) surname(s) and the year of publication (e.g. Salem, 2020). References with two authors should be cited with both surnames (e.g. Salem and Meshrif, 2021). References with three or more authors should be cited with the first author followed by et al. (in italics; e.g. Salem et al., 2021). Names of organizations used as authors (e.g. Food and Drug Administration) should be written out in full in the list of references and on the first mention in the text. Subsequent mentions may be abbreviated (e.g. FDA).

- List of references. Literature cited should be listed in alphabetical order by authors' names. It is the author's responsibility to ensure that all references are correct. All authors should be written and so the full journal name.

- References from journal articles are formatted in APA as this example: Al-Amoudi WM (2018). Toxic effects of Lambda-cyhalothrin on the rat thyroid. Involvement of oxidative stress and ameliorative effect of ginger extract. Toxicology Reports, 5: 728-736.

- References from books or official reports are formatted as this example. Kebreab E, Dijkstra ANM, Bannink A, Gerrits WJJ, \& France J (2006). Nutrient digestion and utilization in farm animals. CABI Publishing. Wallingford, UK.

- References from chapters or parts of books are formatted as this example. Nozière $P, \&$ Hoch $T$ (2006). Modelling fluxes of volatile fatty acids from rumen to portal blood. In: Nutrient digestion and utilization in farm animals (Kebreab E, Dijkstra ANM, Bannink A, Gerrits WJJ \& France J, eds.), pp. 40-47. CABI Publishing. Wallingford, UK.

Tables:

The data should be presented in tables or in graphs, not both.

- Each table should be placed on a separate page at the end of the main text.

- Tables are numbered consecutively using Arabic numbering. They are referred to as Table 1 , Table 2, etc., with capital ' $T$ ', no italics

- Each table has its explanatory caption. The caption is sufficient to permit the table to be understood without reference to the text.

- Abbreviations used in tables/figures have to be defined either as footnotes or in the caption.

Figures

- Package the figures in a single PowerPoint file. Each figure in a separate slide.

- Figure size should be readable in a width of approximately 8-175 $\mathrm{mm}$ (i.e. the maximum size of printing over two columns).

- Ensure that the font size is large enough to be readable at the final print size, use Calibri font to ensure that they are consistent throughout the figures.

- The figures should preferably be provided as TIFF or EPS files.

- The resolutions of figures must be at least $300 \mathrm{dpi}$.

- Preparation of images for a manuscript: For guidance, we refer to the Journal of Cell Biology's instructions to authors (http://jcb.rupress.org/site/misc/ifora.xhtml\#image_aquisition).

- If a cropped image is included in the main text of a paper (e.g. a few lanes of a gel), display the full original image, including the appropriate controls, the molecular size ladder and/or the scale as relevant, as a single figure in a Supplementary Material file to facilitate peer-review and for subsequent online publication.

- Supplementary material is submitted along with the main manuscript in a separate file and identified at uploading as "Supplementary File - for Online Publication Only" The title of the article is included at the top of the supplementary material.

Corresponding author's guidelines: Upon acceptance the corresponding author is required to send his/her recent formal photo to be attached to the front page of the article. 


\title{
International Journal of Cancer \& Biomedical Research
}

(IJCBR) Online ISSN 2682-2628

\author{
Editor-in-Chief \\ Mohamed Labib Salem, PhD \\ Tanta University, Egypt
}

\begin{tabular}{l} 
EACR Board \\
\hline Nehal Elmashad, MD \\
Tanta University, Egypt \\
Nabil Mohy Eldin, PhD \\
Kafrelsheikh University, Egypt \\
Doaa Al-Ghareeb, PhD \\
Alexandria University, Egypt \\
Abdel-Aziz Zidan, PhD \\
Damanhour University, Egypt
\end{tabular}

\begin{tabular}{l} 
Managing Editor \\
\hline Wesam Meshrif, PhD \\
Tanta University, Egypt \\
Sohaila Galal, PhD \\
Tanta University, Egypt \\
Production and Contact \\
\hline Hamdi Kandil \\
Tanta University, Egypt \\
Email: ljcbr100@gmail.com
\end{tabular}

\section{Advisory Board}

Alberto Montero, MD

Taussig Cancer Center, Cleveland,

USA

Yi Zhang, MD

Zhengzhou University, China

Mark Robunstein, Ph D

Medical University of South

Carolina, USA

Mohsen Farid, Ph D

Derby University, USA

Natarajan Muthusamy, Ph D

Ohio State University, USA

Hideki Kasuya, MD

Nagoya University, Japan

Sherif El-Khamisy, Ph D

Sheffield University, UK

Mohamed Ghanem, Ph D

Kafr Elshikh University, Egypt

Sayed Bakry, Ph D

Alazhar University, Egypt

Sameh Ali, Ph D

Nationa Liver Institute, Egypt

Gamal Badr, Ph D

Assuit University, Egypt

Nadia Hamdy, Pharm D

Ain Shams University, Egypt

\section{Editorial Board}

\section{Clinical studies}

Hesham Tawfik, MD

Tanta University, Egypt

Mohamed Attia, MD

Tanta University, Egypt

Mohamed Elshanshory, MD

Tanta University, Egypt

Essam Elshiekh, MD

Tanta Cancer Center, Egypt

Rasha Eraky, MD

Tanta University, Egypt

Shaima Abou-Kjatwa, MD

Tanta University, Egypt

Marcela Diaz, MD

Cleveland Clinic Foundation, USA

Mohamed Abou-El-Enein, MD

Charité Universitätsmedizin Berlin,

Germany
Alaa Eldin Almostafa, MD

McGill University, Canada

Olfat Gadallah, MD

Tanta University, Egypt

Nagla Sarhan, MD

Tanta University, Egypt

Naglaa Fathy, Pharm D

Zagazik University, Egypt

Mohamed Salama, MD

Mansoura University, Egypt

Mona Marie, MD

Alexandria University, Egypt

Preclinical studies

Mostafa El-Sheekh

Tanta University, Egypt

El-Refai Kenawy, Ph D

Tanta University, Egypt

Mohamed Noureldin, Ph D

Banaha University, Egypt

Yousry Albolkiny, Ph D

Tanta University, Egypt

Elsayed Salim, Ph D

Tanta University, Egypt

Shengdian Wang, Ph D

Chinese Academy of Sciences,

China

Sabry El Naggar, Ph D

Tnata Univesity, Egypr

Faris Alenzi, Ph D

Prince Sattam bin Abdulaziz

University, KSA

Ibrahim El-Sayed, Ph D

Menoufia University, Egypt

Tarek Aboul-Fadl, Ph D

Assiut University, Egypt

Rabab Khairat, Ph D

National Research Center,

Giza, Egypt

Wael Lotfy, Ph D

Alexandria University, Egypt

Ashraf Tabll, Ph D

National Research Center, Egypt

Nahla Shoukry, Ph D

Suez University, Egypt
Medhat Eldenary, Ph D

Tanta University, Egypt

Azza Hasan, Ph D

Menufia University, Egypt

Nanees Gamal Eldin, Ph D

Tanta University, Egypt

Mohamed Mansour, UK

Sabbah Hammoury, Ph D

Alexandria Ayadi Almostaqba

Oncology Hospital, Egypt

Nehal Aboulfotoh, Ph D

Zewail City for Science and

Technology, Cairo, Egypt

Amir Elkhami, Ph D

Galaxo, San Francisco, USA

Ahmed Alzohairy, Ph D

Zagazi University, Egypt

Wgady Khalil, Ph D

National Research Center, Egypt

Amr Amin, Ph D

United Arab Emirates

University, UAE

AbdelRahman Zekri, Ph D

National Cancer Institute, Egypt

Hussein Khamis, Ph D

Alexandria University, Egypt

Magdy Mahfouz, Ph D

Kafr Elsheikh University, Egypt

Ehab Elbedewey, Ph D

Tanta University, Egypt

Abeer Badr, Ph D

Cairo University, Egypt

Mamdooh Ghoneum, Ph D

Charles Drew University of

Medicine \& Science, USA

Haiam Abou Elela, Ph D

National Institute of Oceanography and Fisherie, Egypt

Maha EL-Demellawi, Ph D City for Scientific Research \&

Technology Applications, Egypt

Desouky Abd-El-Haleem, Ph D

City for Scientific Research \&

Technology Applications, Egypt 